La Tribuna. Cadernos de Estudos da Casa-Museo Emilia Pardo Bazán

Núm. 9, $121-142$

(C) 2012-2013. Casa-Museo Emilia Pardo Bazán

\title{
Dona Emilia en Compostela ${ }^{1}$
}

\author{
José Manuel González Herrán \\ (UNIVERSIDADE DE SANTIAGO DE COMPOSTELA) \\ josemanuel.gonzalez.herran@usc.es
}

A Euloxio R. Ruibal

(recibido outubro/2013, revisado novembro/2013)

RESUMEN: Se estudia tanto la presencia de la escritora en Santiago de Compostela (visitas, estancias, relaciones, recuerdos, testimonios...), como la huella de la ciudad compostelana en su obra (escenario de novelas y cuentos; fuente de asuntos para sus relatos y crónicas; tema de ensayos, conferencias, artículos...).

PALABRAS CLAVE: Emilia Pardo Bazán, Santiago de Compostela.

ABSTRACT: This paper aims at studying both the presence of the writer in Santiago de Compostela (visits, stays, relations, memories and evocations), and the traces of this city in her works (setting of novels and short stories, source for her narrations and chronicles, subject of essays, conferences and articles...).

KEY WORDS: Emilia Pardo Bazán, Santiago de Compostela.

Trato aquí de "Dona Emilia en Compostela": é dicir, da súa presenza nesta cidade, e mais da presenza da cidade na súa obra; da súa relación coa sociedade compostelá, e as súas institucións; pero tamén -e sobre todo- de Santiago de Compostela na súa literatura: sexa como escenario de novelas e contos, como fornecedora de asuntos para as súas historias e crónicas; como tema dos seus ensaios, conferencias e artigos xornalísticos. Un aspecto que non é menor nin na súa biografía nin na súa obra: por suposto que dona Emilia era coruñesa e a súa cidade (que ela literariamente bautizou como "Marineda") ocupa lugar preferente na súa peripecia vital, na súa actividade cultural, e nos seus escritos. Pero Compostela non fica atrás, ata o punto de que, con Madrid e París, forma parte do núcleo predilecto na súa xeografía persoal e literaria.

\footnotetext{
${ }^{1}$ Texto baseado na miña conferencia no Ateneo de Santiago o 18 de febreiro de 2013. Para a súa elaboración valinme de outro texto meu (agora ampliado e actualizado), que foi relatorio nun coloquio en Francia en novembro de 2005, e publicado ao ano seguinte (González Herrán 2006) nun volume que non tivo moita circulación, fóra dos círculos do hispanismo francés.
} 
Imos, pois, ó que nos ocupa, comezando polos testemuños más temperáns que coñecemos. Sen dúbida, Santiago, para unha familia coruñesa que se movía con frecuencia entre os lugares cos que mantiña máis vínculos (Coruña, Meirás, Carballiño, Sanxenxo...) tivo que ser paso obrigado, con frecuente aloxamento e visita ocasional aos parentes que alí tiña. Ata que, en 1868 (o ano en que estoupou a revolución, pero tamén o ano en que Emilia casou$^{2}$ ) se produce a primeira estancia demorada.

Ó iniciarse o curso académico 1868-1869 a rapaciña Emilia Pardo Bazán, unha recén casada que só conta dezasete anos, instálase en Santiago de Compostela, onde o seu esposo, José Quiroga y Pérez de Deza, vai comezar os estudos de Dereito ${ }^{3}$. Non sabemos exactamente onde residiu a parella: aínda que cabería esperar que se aloxasen en casa de algúns dos seus parentes en Santiago, parece que non foi así. Nun artigo publicado na revista La Ilustración Artística, de Barcelona, en 1912, a Condesa recordaba, refiríndose ás tradicionais casas de hóspedes:

He residido, en Santiago de Compostela, en una que era un portento, de la cual conservo los recuerdos más agradables. Allí se dormía en sábanas bordadas de hilo, y bajo colchas de damasco rojo, de hábito de prelada; allí se comía como en la propia casa, las mejores piezas que del mercado salían, y la huéspeda, cariñosa, preguntaba, de víspera, iqué nos pedía el apetito! Allí se servía el chocolate en bandejas y salvillas de maciza plata, y nos alumbrábamos con los candelabros señoriles, de muchos brazos, de peso de varias libras... Y allí -recuerdo que me hace sonreír aún- nos presentaban cada día, al almuerzo como a la cena, cuado no a la merienda, una caja entera de mermelada de membrillo o ciruela "de las monjas", y cuando yo preguntaba qué hacían de tantas cajas empezadas apenas, me contestaba la buena señora, sencillamente: "Después de empezarlas ustedes, las acaban los estudiantes de arriba" (Pardo Bazán: 1912).

Pero esa estadía non duraría moito: o 27 de xaneiro de 1869 en instancia dirixida ó Reitor da Universidade compostelá, José Quiroga solicita o traslado da súa matrícula á Central, para fixar a residencia da parella en Madrid, onde o pai de Emilia ten que ocupar o seu escano como deputado nas Cortes Constituíntes. E como o solicitante é aínda menor de idade, o escrito leva ó pé da sinatura "con mi consentimiento, José Pardo Bazán" (Acosta 2007: 85). O esposo de dona Emilia, con sucesivos traslados de expediente entre Madrid e Santiago, licenciouse na nosa Universidade en outubro de 1871. Xosé Ramón Barreiro, tras consultar o expediente persoal de José Quiroga, conservado no Arquivo Histórico da USC, amosou como, despois de aquel traslado

\footnotetext{
2 “Tres acontecimientos importantes en mi vida se siguieron muy de cerca: me vestí de largo, me casé y estalló la Revolución de septiembre de 1868” (Pardo Bazán 1999: 18).

3 "En Santiago se instala el joven matrimonio para que el marido estudie el penúltimo curso de la Licenciatura de Derecho en la Universidad" (Bravo-Villasante 1962; Bravo-Villasante: 1973: 28); biografías más recentes (Faus 2003, I: 115 y 129; Acosta 2007: 80-85), corrixen o dato.
} 
á Central, o seu expediente retorna á de Santiago en 1870, para volver de novo a Madrid; e precisa: "Mal estudiante, suspende varias asignaturas o no se presenta a los exámenes. Todo esto cambia entre 1870 y 1871 en que, sin duda apoyado de cerca por doña Emilia, fue capaz de aprobar ocho asignaturas, favorecido en este caso por la legislación vigente, obra de Ruiz Zorrilla, que permitía a los alumnos examinarse cuando ellos querían, o trasladar la matrícula entre las universidades a gusto del alumno (...) El 19 de octubre de 1871 se examina en Santiago de Compostela del grado de Licenciado en Derecho Civil y Canónico (...), obteniendo la calificación de aprobado". (Barreiro Fernández 2006: 27).

Con todo, aínda que non tivese nada que ver cos estudos do seu esposo, hai constancia de que entre o 68 e o 74 Emilia pasa tempadas na cidade do Apóstolo, cuxa vida estudiantil recreará na súa novela Pascual López: un temperán exemplo nas letras españolas do que hoxe en día chamamos novela de ciencia-ficción; ou, mellor, de anticipación científica, considerando o adiantado dos experimentos e aparellos dun profesor da Universidade compostelá, Félix O’Narr, irlandés, quen pretende, mediante unha complexa máquina da súa invención e que para o seu arriscado manexo necesita da axuda do estudante Pascual, a fabricación do diamante artificial; aspiración que non inventa dona Emilia, senón que, por eses mesmos anos, se discutía non só nas publicacións especializadas, senón tamén en revistas de índole cultural e literaria, como a coruñesa Revista de Galicia, que dirixía dona Emilia (Rodríguez Mourelo 1880). Non repetirei agora o que expliquei nun traballo recente, a propósito dos fundamentos científicos daquela novela (González Herrán 2012) e que ten que ver co feito de que a escritora coruñesa establecera coñecemento con algúns profesores e científicos da Universidade de Santiago: Laureano Calderón, José Rodríguez Mourelo, José Rodríguez Carracido, e -sobre todo- Augusto González de Linares, con quen mantivo unha estreita e cordial amizade -segundo amosan as cartas conservadas (Faus 1984) - e que algunha das súas biógrafas propón considerar como un amor platónico de dona Emilia (Faus 1984: 271-282; reitérao, case de maneira literal en Faus 2003: 135-135).

Pero deixemos para outra ocasión ese aspecto das súas relacións, o que agora me importa é lembrar que o cántabro González de Linares era un destacado krausista e institucionista, amigo de Giner de los Ríos (con quen puxo en contacto á coruñesa) e un dos introdutores das teorías de Darwin en España: foi moi sonada a conferencia que deu sobre ese asunto no salón artesoado de Fonseca, en 1872, e que orixinou unha polémica, principalmente cos elementos máis levíticos da cidade ${ }^{4}$. Cando, tres

\footnotetext{
4 Ademais de Alonso Montero 1982, véxase agora Díaz-Fierros Viqueira (ed.) 2009. A noticia máis completa daquela disertación procede dun dos presentes nela, José R. Carracito (1917). Nova luz sobre todo isto será proporcionada moi pronto pola edición das Obras Completas de González de Linares, que publicará a Universidad de Cantabria, preparadas polo meu paisano, colega e amigo Carlos Nieto Blanco.
} 
anos máis tarde, como consecuencia do decreto de Orovio, Linares foi destituído como profesor (e encarcerado na prisión de San Antón, en A Coruña), don José Pardo Bazán intervirá, por intercesión da súa filla, en defensa do profesor castigado ${ }^{5}$. Esa excelente relación dos Pardo Bazán -pai e filla- con Linares era perfectamente compatible coa que tamén mantiñan con quen asinara aquela destitución, o Reitor Antonio Casares Rodríguez, outra destacada figura científica daquela Universidade (e que volverá saír nesta conferencia).

Detívenme en mencionar eses nomes e en aludir ó ambiente intelectual daquela Compostela porque, moi probablemente, de aí deriva a imaxe da nosa cidade que a escritora expresou en varias ocasións. Velaí como o facía nun artigo publicado na citada revista barcelonesa, en 1902:

La calma de Compostela es engañosa. Compostela es como la Edad Media, en la cual, superficialmente, suele verse una época de unidad, y que, estudiada despacio, con documentos y con analítica ojeada, descubre un hervidero de enconadas y violentas pasiones (...) Dormida solo en apariencia, al abrigo de los seculares muros de sus grandiosos templos y conventos, Compostela piensa más que los pueblos fabriles e industriales (...) La tradición, visible en los monumentos, dueña de la ciudad, se presenta como un problema, y fuerzas innovadoras, elementos críticos, actúan e inducen a analizar y a discutir. Nunca como en Compostela he visto que apasionen cuestiones de orden religioso y metafísico; en ninguna parte la neutralidad y el indiferentismo fueron más difíciles de arraigar (Pardo Bazán 1902).

Eses anos composteláns teñen o seu reflexo literario na primeira novela publicada pola autora, Pascual López. Autobiografía de un estudiante de medicina (1879), onde, segundo indica o subtítulo, se recrean as peripecias dun estudante naquela Universidade, nos axitados cursos inmediatos á revolución "gloriosa" do sesenta e oito. O crítico Andrés González Blanco, nun folleto sobre dona Emilia que publicou ó finar esta (1921), afirmaba que, segundo confidencia da autora, a redacción desa novela databa dos anos inmediatamente siguintes ó seu matrimonio. E, refiríndose ó antes mencionado hospedaxe compostelán da xove parella, introducía unha comparación moi pertinente: "una casa de huéspedes con honores de fonda, la cual tenía en su piso superior una auténtica y legítima casa de huéspedes, una "Casa de la Troya»". Esa alusión á coñecida novela de Alejandro Pérez Lugín (1915) é con toda seguridade moi deliberada por parte do crítico; con el, varios estudosos da obra de dona Emilia, como o meu recordado mestre don Benito (Varela Jácome 1973: 156161), teñen observado a relación e similitude entre esas dúas novelas, Pascual López e La Casa de la Troya, ambientadas no mundo estudiantil compostelán.

\footnotetext{
5 En carta de Emilia Pardo Bazán a Giner de los Ríos datada o 9 de outubro de 1879, alude ás súas xestións co Gobernador de A Coruña para que non se encarcerase a Linares, a cambio de pagar unha forte multa (carta $\mathrm{n}^{\circ}$ 10, en J. L. Varela 2001: 383); véxase tamén a carta do propio González de Linares a Giner, o 26 de abril de 1875, recollida en Faus 1986: 199-202.
} 
Pero, ademais, ese libro de Pardo Bazán é importante prá configuración literaria de Compostela, como unha das primeiras -e máis valiosas- novelas que ambientan a súa ficción na capital de Galicia. Nesa serie literaria, a primeira novela de Pardo Bazán ocupa un lugar sobranceiro e, en certa medida, fundador. A pequena cidade que era por entón Santiago recréase literariamente de maneira moi precisa nas páginas de Pascual López. E, entre os lugares expresamente mencionados, a Catedral, o seu Pórtico da Gloria, a Capela da Soedade, a da Corticela, a fachada das Praterías, a Porta Santa, a praza da Quintana; espazos urbanos como o Preguntoiro, a praza do Toural, o Mercado Vello, as rúas Nova e do Vilar, o Convento da Ensinanza, San Francisco, Santo Agostiño, a Compañía de Xesús; ou os lugares frecuentados polos estudantes, como as aulas universitarias, a Facultade de Medicina, a fachada do edificio central do Alma Mater, o "paraíso" do Teatro, o Pazo de Bendaña, o Instituto, as fermosas paraxes da Alameda; ou, arredándonos do núcleo urbano, o Pico Sacro, o Río dos Sapos, o monte Pedroso, os Agros de Carreira... (resumo da nosa "Introducción" a Pardo Bazán 1996: 36-37).

Sirva como mostra -entre outras moitas que poderían citarse- esta primeira descrición da cidade, no capítulo primeiro:

Monumentales edificios, altas iglesias con grandes retablos de amortiguado oro, calles estrechas e irregulares con arcos de soportal, que parecen hechos de encargo para misterios y tapujos, y de vez en cuando cortadas por la imponente mole de alguna blasonada y desierta casa solar o de algún convento de verdinegras tapias y rejas mohosas; paseos cuyos árboles se deshojan lentamente y sus hojas mueren bajo los pies de escasos transeúntes; alrededores apacibles, mudos, verdes y frondosos a causa de la humedad, pero sellados con la tristeza peculiar de los países de montaña: tal es Santiago. De día, a la luz del sol, la Jerusalén de Occidente (que así suele ser nombrada en elegante estilo), parece venerable y pacífica, sin austeridad ni ceño; pero en las largas noches invernales, cuando en las angostas calles se espesa la oscuridad y la enorme sombra de la Catedral se proyecta en el piso de la Quintana de muertos y el reloj cuenta las horas con lengua de bronce, y la luna vierte vaporosas olas de luz sobre las caladas torres, la impresión que produce Santiago es solemne. ¡Oh, si yo fuera dado a filigranas poéticas! ¡qué linda ocasión se me ofrecía para describir los efectos de perspectiva que en la serenidad nocturna producen los majestuosos edificios, mudos testigos de la muerta grandeza de tan ilustre ciudad! (Pardo Bazán 1996: 58-59).

Mais non era este o primeiro achegamento literario de Emilia Pardo Bazán á cidade do Apóstolo. Ela mesma, no seu prólogo á novela, explicando as razóns da súa especial predilección por aquela cidade, aludía de maneira imprecisa ó que chama "primicias de mi imaginación adolescente", inspiradas por Compostela:

Los sucesos de esta historia pasan en un pueblo de mí tan preferido y visitado como Santiago. Me inspiran singular predilección e interés las ciudades antiguas y melancólicas, envueltas en sus recuerdos, como un rey caído en el armiño y 
púrpura marchita de su augusto manto (...) De todos estos sarcófagos imponentes [citara Toledo, Burgos, Salamanca], el que más huella imprimió en mi fantasía fue Santiago (...) porque hubo de ser la primera que en la aurora de la vida despertó mi mente a la contemplación de edades muertas, bajo los pilares de su Catedral y en las revueltas de sus tortuosas calles. Consagrele las primicias de mi imaginación adolescente, y a despecho de cuantas maravillas arqueológicas pude más tarde admirar en mi patria y en extrañas tierras, no se borró jamás aquella impresión viva y temprana (Pardo Bazán 1996: 54).

Pois ben: logo das nosas pescudas na obra temperá da autora, podemos precisar cales foron esas primicias da súa imaginación adolescente, consagradas a Compostela. A máis antiga data de cando a novísima escritora contaba quince anos (teñámolo en conta, antes de xulgar as súas calidades literarias): un longo poema de sesenta e catro versos titulado "A Santiago", cuxa copia manuscrita autógrafa (no chamado Álbum de poesías, que se garda na Fundación Lázaro Galdiano, de Madrid) indica ó final: "En el álbum de Teresa Rúa [acaso prima de Emilia]. Santiago, 1876" (Hemingway 1996: 34-35). O poema é unha despedida da cidade, da que menciona algunhas belezas monumentais:

Tranquila ciudad hermosa

de tantos recuerdos Ilena

tan reposada y serena

como imponente y grandiosa

(...)

Cual labrada filigrana

que en el aire se sustenta

la esbelta torre se ostenta

del lado de la Quintana;

y cada vez que la veo

más se impone en mi memoria

la fachada de la Gloria,

obra inmensa de Mateo.

Enfrente al altar de plata

donde entre encendida cera

al Apóstol se venera,

el corazón se dilata;

y preséntanse a la mente

los antiguos peregrinos,

que por distintos caminos

venían devotamente... 
Digamos que entre os poemas xuvenís de Emilia (algúns dos cales se foron descubrindo e publicando nestes últimos anos), hai varios que aparecen datados nesta cidade; un deles, titulado "Improvisación", consta como "leído en el Casino de Santiago" en 1871: refírese sen dúbida ó Casino Carlista, en cuxas reunións parece que a poeta mociña -tan carlista daquela como o seu esposo- deu a coñecer outras composicións, tan significadas politicamente como este "Brinde":

Yo brindo por el Rey que en el destierro

guarda el honor y el brío castellano,

y brindo por poder en breve tiempo

besar su augusta mano (Hemingway 1996: 72).

Este e outros poemas converten á señora de Quiroga en poetisa oficial do carlismo galego. E a ese respecto, cabe recordar aquí un suceso que contou Xosé Ramón Barreiro, no seu libro de 1976 sobre o carlismo galego:

El más importante [de los casinos carlistas en Galicia] fue el de Santiago, inaugurado con toda solemnidad el 24 de abril de 1870. Pero los festejos de la inauguración se vieron desagradablemente interrumpidos por una multitudinaria manifestación, formada por los más diversos sectores políticos de la ciudad, en la que destacaban los republicanos. La manifestación atacó a los señores de levita y a las señoras encopetadas (la mejor sociedad de Santiago) que descendían de los carruajes para iniciar el baile. Desde las casa vecinas (el Casino carlista estaba en el número 25 de la Rúa Nova) fueron apedreadas las ventanas y puertas del inmueble. (Barreiro Fernández 1976: 249 e 252):

A ese episodio referirase a moza poetisa en outro dos seus poemas de entón, leído tamén naquel casino:

Era usanza en rancios días

que a las damas, donde quiera,

homenaje se rindiera

de amable galantería.

Hoy les brinda el siglo, esquivo

a todo culto perfil,

en vez de ternezas mil,

un muera provocativo. (Hemingway 1996: 101-102).

Máis interese ten, polas súas referencias compostelás, outro poema, datado en 1875 e titulado "En el cementerio de San Francisco / oyendo los gritos de la plaza de toros"; destinado a formar parte do que sería o seu primeiro libro de versos, Himnos y sueños, que nunca chegou a publicar, pero que tamén se conservou manuscrito; di así: 
El augusto silencio de la muerte profundo y religioso rompieron de improviso los clamores de la plaza de toros.

Así el dulce vibrar de las estrellas en las noches de otoño suele turbar de pronto, de un relámpago el brillo sulfuroso. ${ }^{6}$

Trátase dun poema de circunstancias no que a anécdota pretende máis amplo alcance, como alegoría ou símbolo de certa trascendencia. Para explicar o sentido destes versos hai que advertir que en algún deses anos, con ocasión das festas do Apóstolo Santiago, no mes de xullo, instalárase algo parecido ó que hoxe chamariamos unha praza portátil de touros na Praza do Obradoiro, fronte á catedral, con grande escándalo de amplos sectores da vida compostelá; non sería raro que alguén chamase a atención sobre a irreverencia que supoñía a proximidade de tal espectáculo coas cerimonias relixiosas que poideran estarse a celebrar simultaneamente tanto na catedral como nos moitos templos que abundan no casco vello da cidade. A rapariga (cuxo forte conservadurismo, no social e no religioso, se amosa en outros textos seus deses anos) imaxina unha coincidencia que ben puido terse producido: a non moitos metros daquela praza está o cemiterio conventual de San Francisco -que aínda hoxe se utiliza para soterrar os frades desa comunidade, e tamén os membros da chamada "Orde Terceira"-, de modo que o clamor da corrida rompería o fúnebre silencio da cerimonia. Esa hipotética irreverencia é a que explica o ton censor que tinxe o poema co seu "brillo sulfuroso"; é dicir, demoníaco.

Rematemos esa referencia á etapa poética de Pardo Bazán (que pronto abandonou e que coñecemos polos manuscritos do legado pardobazaniano que se conserva no Arquivo da Real Academia Galega, en A Coruña; vid. González Herrán 2005) mencionando o recoñecemento público da súa "Descripción de las Rías Bajas", que acadou o primeiro accésit no certame poético celebrado en Santiago o 28 de xullo de 1875, e cuxo premio obtivo don Ramón del Valle, pai do autor de Divinas palabras (Hemingway 1996: 102-106, e nota 26 en pp. 167-168).

Como consecuencia do prestixio literario que paulatinamente ía adquirindo a nosa autora, e tamén das súas relacións con personaxes do claustro da Universidade, en xuño de 1875, don Gumersindo Laverde Ruiz -catedrático en Compostela e mentor de Menéndez Pelayo- escribe ó seu discípulo: "Añada usted a la lista de escritoras el nombre de Emilia Pardo Bazán, coruñesa, cuya firma se ve en varios periódicos

\footnotetext{
${ }^{6}$ Cito e comento este poema no meu artigo González Herrán 2003.
} 
gallegos $^{\prime 7}$; máis adiante, en agosto de 1878, recomenda ó seu paisano que lea e se poña en contacto coa coruñesa ("señora de extraordinarias prendas intelectuales. Sin maestro, en poco tiempo, ha aprendido varias lenguas y $\operatorname{ciencias}^{\prime \prime}$ ), e serve de intermediario para que ambos inicien unha relación (primeiro epistolar, logo -xa en Madrid-, persoal) que se prolongaría durante máis de trinta anos (González Herrán 1986-1987, e González Herrán 2002). A propósito desa relación, non me resisto a citar un testemuño pouco coñecido, procedente dunha carta de don Gumersindo a don Marcelino, onde formula unha arriscada e curiosa hipótese a propósito das calidades de dona Emilia: "Es señora de alientos. Tú y ella habríais hecho un buen matrimonio" ${ }^{\prime 9}$.

Volvamos aos anos 75-79, cando a nosa autora pasaba en Santiago longas tempadas, ocupada en preparar e escribir algúns traballos de divulgación científica e literaria, que publicaría en La Revista Compostelana ${ }^{10}$ e en La Ciencia Cristiana, de Madrid ${ }^{11}$. O traballo máis importante que elaborou neses anos e en Santiago, foi o seu San Francisco de Asís, do cal boa parte das fontes consultou na biblioteca do convento franciscano de Compostela; así o declara -e agradece- ela mesma nun manuscrito, aínda inédito, titulado "A los frailes menores, hijos de San Francisco, de Compostela", datado o 4 outubro (día de San Francisco de Asís, segundo precisa a adicatoria) de 1878, que posiblemente ía a ser unha carta-dedicatoria a modo de prólogo para o libro, que publicaría catro anos máis tarde, pero que non chegou a incluírse nel ${ }^{12}$.

Malia á data desa adicatoria, aínda en abril do 79 seguía preparando o seu San Francisco; sabémolo por un curioso documento: un manuscrito autógrafo da escritora, que se conserva no citado Arquivo da Real Academia Galega, titulado "Diario de mi vida", no que dá conta das súas actividades e ocupacións, en Santiago,

\footnotetext{
${ }^{7}$ Carta do 19 de junio de 1875; nº 211 en Menéndez Pelayo 1982: 239.

${ }^{8}$ Carta do 3 de agosto de 1878; ${ }^{\circ} 131$ en Menéndez Pelayo 1983: 202.

9 “Ayer tuve el alto honor de ser visitado por Emilia Pardo Bazán, a quien no conocía. Una hora pasamos en amena plática, y quedó en volver á verme. Díjome que estaba indecisa entre emprender la composición de una Historia de la literatura castellana por el estilo de la que de la inglesa escribió Taine, o bien la de nuestra riquísima Literatura mística. Yo apoyé con preferencia este segundo proyecto. Es Señora de alientos. Tu y ella habríais hecho un buen matrimonio" (carta do 15 de febrero de 1883; nº 27 en Menéndez Pelayo 1983: 26).

10 En 1876 firma nesa revista os artigos: "Ciencia amena" ( $\left.\mathrm{n}^{\circ} 3\right)$, "El calórico" ( $\left.\mathrm{n}^{\circ} 4,6,7\right)$, "La luz" $\left(\mathrm{n}^{\circ} 8,9,10,11\right)$, "La electricidad" ( $\left.\mathrm{n}^{\circ} 12,13\right)$, "La circulación del movimiento" ( $\left.\mathrm{n}^{\circ} 14\right)$, "Apología del calórico" ( $\mathrm{n}^{\circ}$ 17)

11 “Las epopeyas cristianas. Dante y Milton”, nos tomos II, III e IV; “Reflexiones científicas contra el darwinismo", no tomo V; todos eles, en 1877.

12 Comenta este documento, e cita algún fragmento, Patiño Eirín 2001.
} 
entre o domingo 13 e o venres 25 de abril de $1879^{13}$. O motivo da súa estancia é precisamente investigar con materiais da biblioteca dos franciscanos; así, o mércores 16 escribe: "He extractado un tomo de la Crónica Seráfica para mi obra sobre San Francisco"; o xoves 17: "Hoy he trabajado en grande (...) Tengo esperanzas de salir bien de mi trabajo. Cada mañana me envían los franciscanos un in-folio que me dedico a desentrañar. Llueve, llueve, y tengo instantes de desaliento; pero sigo con la pluma en la mano"; o venres 18: "La historia de mi estancia aquí es la de mis trabajos. Hoy he consagrado a la Crónica franciscana nada menos que ocho horas. El día ha sido bien aprovechado"; o domingo 20: "Con los frailes pasé largo rato. Están entusiasmados con la idea de que voy a hacer una magnífica obra sobre San Francisco. Quiera Dios que no se engañen. Me siento con pocas fuerzas"; o luns 21: "Pasé el día extractando crónicas viejas, ingenuas, apolilladas. Encuentro infinidad de asuntos para leyendas" (vid. Freire López 2004); o martes 22: "Yo trabajé mucho: veo que el siglo XIII se va desembrollando ante mis ojos"; e o mércores 23: "Sigo en mi tarea, y quisiera poder dedicar la noche a ella. ¡El teatro me abruma! Hoy no fui".

Sete anos máis tarde, en los "Apuntes autobiográficos" que escribiu como prólogo para a primeira edición de Los Pazos de Ulloa, evocaba así esas estadías en Santiago:

Siempre que iba por algunos días a Compostela, dedicaba largos ratos a la portería del convento de San Francisco, que por su melancólica situación, su aire de recogimiento y austeridad tiene para mí singular encanto. Horas he pasado allí que cuento entre las más hermosas y apacibles de la vida. Oíase en el patio el rumor monótono y argentino del caño de la fuentecilla que ritmaba las conversaciones de los frailes: ¿de qué hablábamos? (...) hablábamos del Patriarca, de las Florecillas, de los cinco estigmas, de la leyenda maravillosa (...) Empecé por aquel tiempo a escribir el San Francisco. (Pardo Bazán 1999: 37).

Ese estudo biográfico do santo de Asís publicaríase en 1882 (con reedicións en 1886, 1890, 1903); malia que no seu tempo foi unha das obras que máis contribuíron á fama e difusión universal da súa autora, hoxe case ninguén a recorda nin a le: entre outras razóns, porque carecemos de edicións accesibles. Non sería mala idea que para o ano 2014, en que se conmemorará o oitavo centenario da visita a San Francisco a Compostela, se reeditase ese libro.

Volvendo a esas estadías compostelás da autora, sabemos que no 83 está por aquí, preparando outros estudos que nunca chegou a culminar: "Yo me encuentro casi desocupada ahora -escribe a Menéndez Pelayo o 18 de abril de 1883- y con deseos de emprender una obra formal. Dudé entre unas Filósofas y Teólogas y una Historia de la Literatura mística y ascética y por fin arraigó en mí la idea de hacer una

13 Publicado por Simón Palmer 1998; os textos que cito, nas pp. 401-403. 
Historia de la literatura española ${ }^{14}$. Para as pescudas sérvese da moi rica biblioteca da Universidade compostelá. Apoiándose na súa antiga amizade co Reitor Casares, escríbelle en febreiro de 1883, para pedirlle "un señalado favor. Quiero hacer algunos estudios en la Biblioteca de esa Universidad y como las horas en que esta se halla abierta son casi incompatibles con las que yo puedo dedicar a ese objeto, quisiera que usted dispusiese que me abriesen por la tarde la Biblioteca y me dejasen estar allí hasta el anochecer"15. Polo que ela mesma contaría anos máis tarde nos citados Apuntes autobiográficos, o Reitor accedeu á súa petición, mellorando as condicións das consultas: "como por entonces entretenía un mes de invierno [febreiro do 83] en Santiago, me dediqué a revolver la Biblioteca de la Universidad (...) Cedióme el Rector galantemente su propio despacho, ordenando que me Ilevasen cuantos libros eligiese" (Pardo Bazán 1999: 41).

A propósito desas esporádicas estadías compostelás de dona Emilia, temos unha interesante noticia, nunha semblanza necrolóxica anónima, titulada "La Condesa de Pardo Bazán", publicada na revista Unión Iberoamericana, de Madrid, poucas semanas despois da morte da escritora; o ton do escrito revela que se basea en confidencias persoais de dona Emilia ó anónimo autor, que acaso fose don Juan Armada y Losada, marqués de Figueroa, parente e amigo de dona Emilia, presidente daquela de "La Unión Iberoamericana". Alí alude ás visitas de Emilia e mailos seus á casa dos Armada, na Rúa Nova; casa que, segundo me di Xerardo Estévez (en mensaxe electrónico do 1 de xuño de 2012), era o palacio dos marqueses de Santa Cruz [de Rivadulla], actual residencia das monxas do Servizo Doméstico, na Rúa Nova, número 9.

Logo das ocasionais alusións á cidade del Apóstol que viñemos comentando nos primeiros escritos de Pardo Bazán, vaiamos xa ás que aparecen nas súas obras maiores. Imos comezar por Los Pazos de Ulloa (unanimemente considerada como a súa mellor novela), onde dona Emilia regresa á súa querida Compostela; pero esta vez, por necesidades argumentais, a consideración que da cidade nos ofrece o narrador é moi diferente á que ela mesma tiña. Como é sabido, a maior parte do relato ten unha ambientación rural, en terras da Galicia interior; pero ocasionalmente, nos capítulos IX a XIII, o marqués de Ulloa pasa unha tempada na casa do seu tío e súas curmás en Santiago, para elixir en matrimonio a unha delas. A voz do narrador, adoptando o punto de vista do personaxe forasteiro - un fidalgo rural acostumado a outras paisaxes e modos de vida- ofrécenos unha visión moi pouco favorable da cidade:

\footnotetext{
${ }^{14}$ Carta no 83 en Menéndez Pelayo 1983: 94. Téñome ocupado con certa miudeza deses proxectos de dona Emilia en González Herrán 2003.

15 Citamos e localizamos esa carta na nota 26 da "Introducción" a nosa ed. de Pascual López (Pardo Bazán 1996: 22-23).
} 
Pareciéronle, y con razón, estrechas, torcidas y mal empedradas las calles, fangoso el piso, húmedas las paredes, viejos y ennegrecidos los edificios, pequeño el circuito de la ciudad, postrado su comercio y solitarios casi siempre sus sitios públicos; y en cuanto a lo que en un pueblo antiguo puede enamorar a un espíritu culto, los grandes recuerdos, la eterna vida del arte conservada en monumentos y ruinas, de eso entendía don Pedro lo mismo que de griego o latín. ¡Piedras mohosas!

(...)

Es cierto que Santiago poseía dos o tres edificios espaciosos, la Catedral, el Consistorio, San Martín... Pero en ellos existían cosas muy sin razón ponderadas, en concepto del marqués: por ejemplo, la Gloria de la Catedral. ¡Vaya unos santos más mal hechos y unas santas más flacuchas y sin forma humana!, ¡unas columnas más toscamente esculpidas! Sería de ver a alguno de estos sabios que escudriñan el sentido de un monumento religioso, consagrándose a la tarea de demostrar a don Pedro que el pórtico de la Gloria encierra alta poesía y profundo simbolismo. ¡Simbolismo! ¡Jerigonzas! El pórtico estaba muy mal labrado, y las figuras parecían pasadas por tamiz. Por fuerza las artes andaban atrasadísimas en aquellos tiempos de maricastaña. Total, que de los monumentos de Santiago se atenía el marqués a uno de fábrica muy reciente: su prima Rita (Pardo Bazán 1999: 139-140).

\section{(...)}

No se acostumbraba a la metrópoli arzobispal. Ahogábanle las altas tapias verdosas, los soportales angostos, los edificios de lóbrego zaguán y escalera sombría, que le parecían calabozos y mazmorras. Fastidiábale vivir allí donde tres gotas de lluvia meten en casa a todo el mundo y engendran instantáneamente una triste vegetación de hongos de seda, de enormes paraguas. Le incomodaba la perenne sinfonía de la Iluvia que se deslizaba por los canalones abajo o retiñía en los charcos causados por la depresión de las baldosas. Quedábanle dos recursos no más para combatir el tedio: discutir con su suegro o jugar un rato en el Casino (Pardo Bazán 1999: 167).

(...)

Tampoco allí [en el Casino] se encontraba bien. Sofocábale cierta atmósfera intelectual, muy propia de ciudad universitaria. Compostela es pueblo en que nadie quiere pasar por ignorante, y comprendía el señorito cuánto se mofarían de él y qué chacota se le preparaba, si se averiguase con certeza que no estaba fuerte en ortografía ni en otras ías nombradas allí a menudo. Se le sublevaba su amor propio de monarca indiscutible en los Pazos de Ulloa al verse tenido en menos que unos catedráticos acatarrados y pergaminosos, y aun que unos estudiantes troneras, con las botas rojas y el cerebro caliente y vibrante todavía de alguna lectura de autor moderno, en la Biblioteca de la Universidad o en el gabinete del Casino. (Pardo Bazán 1999: 170).

Con todo, creo que a máis conseguida recreación literaria de Santiago de Compostela na narrativa de Pardo Bazán está na novela curta Belcebú, publicada en 1908 e ambientada en "la metropolitana ciudad de Estela", nome literario que apenas enmascara o de Compostela, no século XVII: escenario moi axeitado para esta sombriza historia de bruxaría e satanismo (como, en certa medida, o era tamén Pascual López); así, xa desde as primeiras páxinas: 
Al través de callejas con soportales, costanillas y escalinatas fuimos a parar frente a un palacio, el más solemne de todos (...) Es difícil decir en qué consiste el toque de señorío y la dignidad en los edificios; sin embargo, nadie ignora qué impresión de respeto causan ciertas piedras antiguas. Quizás el mismo deterioro del palacio, lo negruzco de su cantería, su aire de abandono, prestaban grandiosidad al amplio escudo, con dos sirenas por tenantes. (Pardo Bazán 2002: 344-345.

Ó longo da novela menciónanse diversos lugares -preferentemente, palacios e conventos-, unhas veces cos mesmos nomes que hoxe manteñen (como os conventos da Ensinanza ou de San Francisco), outras, lenemente disfrazados (como o convento de Belvista, onde recoñecemos o de Belvís). Entre os casaróns da cidade, aparece un Pazo dos Marqueses de Noaña, cuxo modelo real é o Pazo de Bendaña, na Praza do Toural: "Este sí que tiene empaque... Qué Atlante el que corona el ático, aguardando, según la tradición, a que pase una mujer de bien, para soltar la bola que agobia sus hombros"; e máis adiante reitera a alusión, agora inserta na trama argumental: "Al cruzar por delante de la casa de los Marqueses de Noaña, el Inquisidor alzó los ojos, miró al agobiado Atlante que parecía sudar y jadear bajo la pesadumbre del globo que sus hombros hercúleos sufrían, y se comparó con él, y la afirmación legendaria acudió a su mente: "Cuando pase una mujer honrada...»" (Pardo Bazán 2002: 343 e 360). Lenda, que -segundo creo- chegou ata os nosos días; polo menos, eu lémbroa dos meus anos estudantís, aínda que o que daquela se dicía era algo diferente ás condicións que había de posuír a muller que provocaría o xesto do Atalante...

Aínda que o escenario da noveliña sexa a cidade de Santiago, a peripecia argumental amplíase ocasionalmente ó ámbito rural inmediato: a familia da protagonista ten o seu Pazo de Landoira, a oito leguas de Estela, "situado a la margen del río Ulla, en la comarca más pintoresca que es dable soñar; (...) una residencia veraniega y otoñal, que competía con las tan ponderadas de Liñares, Ribadulla y Oca" (Pardo Bazán 2002: 352).

Como é sabido, Emilia Pardo Bazán cultivou, con gran dedicación e notable acerto a literatura de viaxes (vid. González Herrán 2000); a maior parte de tales escritos dedícanse a países estranxeiros (Francia, Italia, Alemaña, Bélxica, Portugal...) ou españois (Cantabria, Cataluña, A Mancha, Aragón, ambas Castillas, Levante, Murcia, León, a súa Galicia natal); pero sorprende que, en tan abundante produción, só haxa un artigo dedicado a Santiago de Compostela, o titulado "Impresiones santiaguesas. Una joya del arte renaciente", publicado en diferentes revistas no verán de 1870: primeiro en La Ilustración Gallega y Asturiana, logo na Revista de Galicia e en El Heraldo Gallego e recollido no seu libro de 1888 De mi tierra (en Pardo Bazán 1984: 243-259). Máis estudo histórico que artigo de viaxes, e de carácter menos turístico que científico -como se observa nas eruditas notas a pé de páxina-, trátase dun traballo dedicado a estudar con certo detalle e alarde de datos esa xoia da arte renacentista aludida no título: un altar de mármore no compostelán convento de 
San Lourenzo, cuxa descrición se adorna coa súa historia e a da nobre familia que emprendeu a súa restauración, de modo que, sen desdeñar a rigorosa investigación histórico-arqueolóxica que apoia o traballo, non faltan nel esas evocacións imaxinativas frecuentes na súa literatura de viaxes, que a autora recoñece como manías: "Noto que me pierdo en digresiones de las que siempre me sugiere la vista de cualquier piedra que haya pertenecido a un convento: dejemos ya estas inveteradas manías" (Pardo Bazán 1984: 247).

Pasemos xa a tratar da presenza de Santiago de Compostela na narrativa breve da nosa autora. E o primeiro que importa salientar é que, sorprendentemente sobre todo, se consideramos que os contos escritos e publicados por dona Emilia pasan de 600-, non son moitos os que aquí mencionarei. Limitándonos a aqueles explícitamente localizados en Compostela (que é como dona Emilia denomina sempre a Santiago, cando non emprega o nome literario de Estela), e deixando aparte varios nos que a cidade é unha simple mención, a relación redúcese a sete títulos; todos eles escritos e publicados entre 1890 y 1916. Vexamos nalgúns deles como se reflicten ou se recrean literariamente os escenarios da cidade:

O primeiro ó que me referirei é o moi coñecido e xustamente eloxiado "Un destripador de antaño"; aínda que a meirande parte do asunto deste relato -case novela corta, pola súa extensión- transcorre nun ámbito aldeán, hai varios episodios localizados na cidade do Apóstolo, onde ten a botica don Custodio, personaxe fundamental da historia:

Llegaron a Compostela a tiempo que las campanas de la catedral y de numerosas iglesias tocaban a misa, y entraron a oírla en las Ánimas, templo muy favorito de los aldeanos, y, por lo tanto, muy gargajoso, sucio y maloliente... De allí, atravesando la plaza llamada del Pan, inundada de vendedoras de molletes y cacharros, atestada de labriegos y de caballerías, se metieron bajo los soportales, sustentados por columnas de bizantinos capiteles, y llegaron a la temerosa madriguera de don Custodio (Pardo Bazán 2005: 17).

Nese mesmo libro de 1900 recolleu a autora o relato "La Santa de Karnar", publicado antes en Nuevo Teatro Crítico (1891); a súa historia ten como principal escenario unha remota aldea da montaña galega, onde vive a santa do título; só nas primeiras liñas se alude "a la húmeda atmósfera de Compostela" (Pardo Bazán 2005: 129), onde daquela vivía a nena enferma que, hoxe anciá, conta a historia.

De escenario totalmente santiagués é "El baile del Querubín"; pero, pola localización preferentemente en interiores, moi pouco é o que da cidade aparece no conto: a casa do protagonista-narrador e a da súa tía e curmás ("Vivían mis padres en Compostela, y residían en el caserón de nuestros mayores, edificio vetusto y ya destartalado [...] Próxima a nuestra morada -si bien con fachada y portal a otra calle- hallábase la de la hermana de papá"); os bailes de sociedade, no Liceo e máis 
no Casino; e un encontro na Praza da Quintana, preto xa das Praterías, que dá pé ó narrador para unha rápida descrición do entorno: "la bella fachada gótica de la catedral, que surgía coronando la escalinata [...] allá abajo, en la plaza, la fuente monumental, en cuyo pilón los caballos marinos remojaban sus palmeados pies" (Pardo Bazán 2004: 259, 262 e 263).

O topónimo literario de Estela, que xa vimos en Belcebú, reaparece como a cidade onde ocorre "La Soledad"; os seus protagonistas son dous namorisqueiros estudantes - un de Medicina, outro de Dereito- que dedican o día de Xoves Santo a seguir polas rúas ás damas que acoden aos oficios, ata que se cruzan cunha de feiticeira beleza, extraordinariamente parecida á imaxe da Virxe da Soedade. O final exemplar da historia sitúanos de novo no coñecido escenario do convento de San Francisco: un dos dous escolares, tras superar a enfermidade que estivo a punto de levalo á sepultura, interpretará aquel encontro como un aviso e, escarmentado, “apenas pudo salir a la calle, una tarde larga y serena de fines de junio, llamó a la puerta del convento de Franciscanos" (Pardo Bazán: 2005: 671).

Tamén acontece en Estela a peripecia de "La cana", un dos relatos policiais de dona Emilia, publicado en Los contemporáneos (1911) e recollido o ano seguinte en Cuentos trágicos; pero as referencias ó ámbito urbano redúcense a unha mención a "la plazoleta rodeada de vetustos edificios, donde abre su irregular puerta cochera el parador" (Pardo Bazán 2005: 412), e pouco máis.

Por razóns que se me escapan, pró conto "Cenizas", dona Emilia inventa o topónimo Montañosa para unha cidade cuxo modelo é, sen dúbida, Santiago. Compostelá, e moi coñecida, é a lenda que recrea este conto, malia que a autora modifica tamén os nomes que localizarían os seus escenarios: o convento beneditino de San Paio de Antealtares chámase aquí de San Juvencio; a Praza da Quintana -a Quintana dos Mortos- rebautízase como Plaza de la Muerte:

aquella plaza de la Muerte que forman antiguos edificios, y en cuyos ámbitos retumba pausada, honda, la campana del reloj de la catedral. El tiempo que cuenta esta campana no se parece al tiempo que miden los demás relojes. Es un tiempo marcado con el sello de la eternidad, y al dilatarse en la brumosa atmósfera el grave sonido, diríase que los muertos yacentes bajo las losas de la plaza y que le dan nombre se revuelven en la húmeda tierra y entrechocan sus huesos gimiendo de inmensa fatiga.

\section{(...)}

Forma el convento de San Juvencio, como usted no ignora, uno de los lados de la cuadrilonga plaza de la Muerte. Sus formidables muros, enverdecidos por la humedad, pueden Ilamarse ciegos; apenas los rasgan pocas negras ventanas enrejadas y altísimas; San Juvencio no tiene rejas bajas. La iglesia, cuya portada adorna la efigie del santo degollado, en la agonía y con el cuchillo hincado en la garganta, tampoco posee tribuna baja; la del coro remata en la bóveda. Las monjas ya sabe usted que son benedictinas, muy damas, contemplativas, aristocráticas. 
A lenda, como dixen, é ben coñecida: unha novicia namorada que, ó tentar escapar do convento, se precipita desde a reixa da súa cela ás lousas da praza:

Las devotas que atravesaban la plaza de la Muerte para oír misa de alba en la catedral vieron al pie del muro de San Juvencio el cuerpo ensangrentado e inerte de una novicia. El corro se había formado. Me abrí paso, me acerqué. La cabeza descansaba sobre el primer peldaño de la escalinata que asciende a las Casas del Cabildo. Un hilo de sangre manchaba la sien. Alrededor de la cintura estaban arrolladas las tiras de sábana convertidas en cuerdas. El otro extremo, roto, colgaba allá arriba de la reja, cuyos hierros limados mostraban el boquete por donde, magullándose, habría pasado el cuerpo. Miré con afán el rostro de la novicia. ¡Mis ilusiones! Ni era fea ni bonita: como cien mujeres que andan por ahí. Sus ojos, vidriados, permanecían entreabiertos, con una expresión de espanto, de miedo y de voluntad (Pardo Bazán 2011: 150-153).

O último texto compostelán de dona Emilia ó que quero aludir é practicamente descoñecido, agás para algúns pardobazanistas, xa que corresponde a un dos moitos que a súa autora deixou inéditos e que chegaron ata nós en versión manuscrita. Entre os que non chegou a culminar, está unha novela que se titularía La Esfinge, e que, segundo ela mesma declarou en artigos, cartas e entrevistas, comenzou a redactar en $1897^{16}$, e que, tras sucesivas interrupcións, chegou a alcanzar máis de cen cuartillas. Aínda en 1907 se refire a ese proxecto, que relaciona con outras novelas súas de similares títulos mitolóxico-alegóricos (La Quimera; La sirena negra), pero non sabemos se chegou a rematala. De La Esfinge só coñecemos (de momento, porque las pescudas continúan) vinte e seis cuartillas manuscritas (Clemessy-Legal $1971)^{17}$ do que serían o capítulo primeiro, o segundo e o comezo do terceiro, nunha versión de borrador, pois ten correccións, riscadas e indicacións do tipo: "Esto hay que dialogarlo entre el maestro y el discípulo"; "Todo esto debe servirme en la novela para lo siguiente..."

Para o que aquí nos importa, digamos que a historia ten notables similitudes temáticas e argumentais coa su primeira novela, Pascual López: tamén hai un estudante universitario (por certo, como Pascual, sobriño dun cóengo) e un sabio profesor que ten por confidente das súas investigacións (en este caso, de índole filolóxica: a orixe da linguaxe e das linguas). Aínda que nesta ocasión a autora disfraza os nomes, tanto da cidade como das súas rúas, monumentos e lugares, recoñecemos sen dúbida a mesma vila universitaria na que situou a súa novela de 1879. Abonde a cita dalgúns fragmentos significativos; o primeiro preséntanos ó

\footnotetext{
16 Segundo as testemuñas que recolle e cita Clemessy-Legal (1971).

17 Nas pp. 15-29 do seu artigo transcribe esas cuartillas; aínda que sigo esa transcrición, nalgún momento rectifico a súa lectura, á vista do manuscrito que puiden consultar, na copia que me facilitou a miña colega Cristina Patiño Eirín.
} 
protagonista, Lope, paseando nunha mañá de domingo:

(...) no fue para él desagradable tropiezo encontrar, bajo las arcadas de la Rúa Vieja, de buenas a primeras, con dos muchachas, que llevaban por escolta a un señor de blanco pelo (...)

-¡A dónde van ustedes? ¿A misa, a la Capilla del Purgatorio? (...) No las acompaño. Tengo que ir a ver don Magno, que me ha avisado el último día, en cátedra... Tiene que enseñarme varios libros nuevos. Pero esta tarde, si no salen ustedes a la Alameda...

(...)

Despidióse Lope, y las dos mujeres, dando cada una un brazo al señor ancianísimo lo subieron casi en vilo por las escaleras que conducen a la Catedral. El sobrino del Deán siguió andando, y se metió por una calleja torcida, colocada entre el paredón de un convento y las tapias del jardín de una casa muy antigua, que por las conchas que decoraban su fachada, daba señales de haber pertenecido o pertenecer aún al Cabildo, como otras muchas en la hermosa y monumental Libredón (Clemessy-Legal 1971: 21-23).

No seu percorrido, o estudante pasa a carón de "la fachada meridional de la Catedral, Ilamada de los Orífices", e tras andar por "calles revueltas y tortuosas que transportan la fantasía al siglo XIV, o aún más atrás", chega a unha rúa ampla e despexada "como que caía detrás de la Universidad, hacia donde se encontraba antes la carretera, y que sin duda por ello se llamaba calle del Correo. Allí, lindando con la frondosa y apacible huerta del convento de las Carmelitas, se alzaba una casa nueva, flamante, de cuatro pisos, con galería, portal estucado, balcones de fundición: una casa que en aquella romántica ciudad venía a ser una verdadera elegía". Alí é onde vive "don Magno Clavijo, catedrático de Filología de la Universidad de Libredón", que convocou a Lope para unha entrevista de índole científica.

Nos escasos parágrafos que se conservan do capítulo terceiro, o estudante fai outra visita: esta vez, ás mociñas con quen se atopou pola mañá (e dunha delas -non sabemos de cal- parece namoriscado), e que viven nun lugar cuxo nome (como veciño que son da rúa da Rosa, en Compostela) me desconcertou:

Las cuatro o cuatro y media a lo sumo serían, cuando se dirigió Lope a la Rosaleira. Llamábase así una casita y una huerta de extramuros de Libredón, y acaso el bonito nombre de Rosaleira hubiese sido puesto a la huerta, sabe Dios en qué fecha, a causa de los muchos rosales que en ella crecían.

Lamentablemente, coa descrición desa casiña e a súa horta de roseiras remata esa cuartilla, última das conservadas, e cuxas liñas finais din: "En este capítulo tercero es preciso pintar la casa, la historia y el modo de vivir de las huérfanas..." (ClemessyLegal 1971: 29). 
Referireime, por último, a "La danza del Peregrino" (en Blanco y Negro, 8 de outubro de 1916), mestura de lenda e reportaxe sobre a solemne cerimonia con que se celebra a festa do Apóstolo na catedral compostelá, así evocada:

En aquel templo extraordinario, ante aquel apóstol bizantino, engastado en plata como una perla antigua, de plata el revestimiento del altar, la pesada esclavina, la enorme aureola, destacándose sobre un fondo de talla dorada el inmenso retablo, con figurones de ángeles que tremolan banderas de victoria y moros que en espantadas actitudes se confiesan derrotados, mientras el colosal incensario vuela como un ave de fuego, encandiladas sus brasas por el vuelo mismo, y vierte nubes de incienso que neutralizan el vaho humano de tanta gente rústica apiñada en la nave (Pardo Bazán 2011: 367).

Quede esa brillante e característica imaxe -o botafumeiro visto pola Condesacomo o plano final desa película que lles veño de proxectar e comentar, sobre dona Emilia en Compostela, e Santiago na obra de Pardo Bazán ${ }^{18 *}$.

\footnotetext{
" Este traballo forma parte do proxecto de investigación Ediciones y estudios críticos sobre la obra literaria de Emilia Pardo Bazán (Referencia: FFI2010-18773.FILO), financiado polo Ministerio de Ciencia e Innovación, que dirixo na Universidade de Santiago de Compostela
} 


\section{BIBLIOGRAFÍA}

Acosta, Eva (2007): Emilia Pardo Bazán. La luz en la batalla. Biografía, Barcelona: Lumen.

Alonso Montero, Xesús (1982): "Darwin en Santiago de Compostela (y los orígenes de la Institución Libre de Enseñanza)", Los Cuadernos del Norte, 13, pp. 2-5.

Bravo-Villasante, Carmen (1962): Vida y obra de Emilia Pardo Bazán, Madrid: Ediciones de la Revista de Occidente.

Bravo-Villasante, Carmen (1973): Vida y obra de Emilia Pardo Bazán, segunda edición corrixida e aumentada, Madrid, Magisterio Español.

Barreiro Fernández, José Ramón (1976): El carlismo gallego. Santiago de Compostela: Pico Sacro, 1976.

Barreiro Fernández, Xosé Ramón (2007): "Morrión y Boina el cuento que nos introduce en la militancia carlista de Emilia Pardo Bazán", en J. M. González Herrán, C. Patiño Eirín e E. Penas Varela, (eds.), Actas del Il Simposio "Emilia Pardo Bazán: Los cuentos", A Coruña: Casa-Museo Emilia Pardo Bazán - Real Academia Galega.

Clemessy-Legal, Nelly, (1971): "En torno a unas cuartillas de doña Emilia", Revista Instituto "José Cornide" de Estudios Coruñeses, $\mathrm{n}^{\circ} 7$ (Especial homenaxe a dona Emilia Pardo Bazán), pp. 7-13; 15-29.

Díaz-Fierros Viqueira, Francisco, ed. (2009): O Darwinismo e Galicia, Santiago de Compostela: Servizo de Publicacións e Intercambio Científico da USC.

Faus, Pilar (1984): "Epistolario Emilia Pardo Bazán - Augusto González de Linares (1876-1878)", Boletín de la Biblioteca de Menéndez Pelayo, LX, pp. 271 313.

Faus, Pilar (1986): Semblanza de una amistad. Epistolario de Augusto G. de Linares a Francisco Giner de los Ríos (1869-1899), Santander, Ediciones del Ayuntamiento de Santander.

Faus, Pilar (2003): Emilia Pardo Bazán. Su época, su vida, su obra, A Coruña, Fundación Pedro Barrié de la Maza.

Freire López, Ana M $M^{a}$ (2004): "Las leyendas que nunca escribió Emilia Pardo Bazán. (Un desconocido proyecto de juventud)", en I. Lerner, R. Nival, A. Alonso (eds.): Actas del XIV Congreso de la Asociación Internacional de Hispanistas, III, Literatura Española Siglos XVIII-XX, Newark, Delaware, Juan de la Cuesta, pp. 209219.

González Blanco, Andrés (1921): Juicio crítico de la Condesa de Pardo Bazán, Madrid: "La Novela Corta", 1921 [sen paxinar]. 
González Herrán, José Manuel (1986-1987): “Emilia Pardo Bazán en el Epistolario de Menéndez Pelayo", CEG, 101, pp. 325-342;

González Herrán, José Manuel (2000): “Andanzas e visións de dona Emilia (A literatura de viaxes de Pardo Bazán)", Revista Galega do Ensino, no 27, pp. 37-62

González Herrán, José Manuel (2002): “Emilia Pardo Bazán. Introducción”, cap. III de Marcelino Menéndez Pelayo, Antología Comentada, Santander, Ediciones de Librería Estvdio, pp. 101-112.

González Herrán, José Manuel (2003a): “Emilia Pardo Bazán: historiadora y crítica de la literatura", en A. Ma Freire (ed.): Estudios sobre la obra de Emilia Pardo Bazán. A Coruña, Fundación Pedro Barrié de la Maza, pp. 81-100.

González Herrán, José Manuel (2003b): "Emilia Pardo Bazán y la fiesta de los toros (1875-1921)", en: A. García-Baquero González y P. Romero de Solís (eds.): Fiestas de Toros y Sociedad, Sevilla, Fundación Real Maestranza de Caballería de Sevilla - Universidad de Sevilla, pp. 591-603.

González Herrán, José Manuel (2005): “Manuscritos e inéditos de Emilia Pardo Bazán (en el Archivo de la R.A.G)", en: J. M. González Herrán, C. Patiño Eirín e E. Penas Varela, (eds.): Actas del Simposio "Emilia Pardo Bazán: estado de la cuestión", A Coruña: Casa-Museo Emilia Pardo Bazán, pp. 33-66.

González Herrán, José Manuel (2006): “Emilia Pardo Bazán y Santiago de Compostela"), en Parcours et repères d'une identité régionale: la Galice au XXè siècle. Culture Hispanique, Hispanística XX [Centre d'Etudes et de Recherches Hispaniques du XXè siècle, Université de Bourgogne, Dijon], nº 23, pp. 257-275.

González Herrán, José Manuel (2012): "Antonio Casares Rodríguez y Emilia Pardo Bazán", Boletín das Ciencias, XXVI, n 75, pp. 177-187.

Hemingway, Maurice, ed. (1996): Emilia Pardo Bazán, Poesías inéditas u olvidadas, Exeter: University of Exeter Press.

Menéndez Pelayo, Marcelino (1982): Epistolario, ed. de M. Revuelta Sañudo, volume I, Madrid, Fundación Universitaria Española.

Menéndez Pelayo, Marcelino (1983): Epistolario, ed. de M. Revuelta Sañudo, volume III, Madrid, Fundación Universitaria Española.

Menéndez Pelayo, Marcelino (1983): Epistolario, ed. de M. Revuelta Sañudo, volume VI, Madrid, Fundación Universitaria Española.

Pardo Bazán, Emilia (1882): San Francisco de Asís (siglo XIII), Madrid, Librería de Miguel Olamendi.

Pardo Bazán, Emilia (1886): San Francisco de Asís (siglo XIII), con prólogo de Marcelino Menéndez Pelayo, París. Garnier [reimpreso en 1890].

Pardo Bazán, Emilia (1902): "La vida contemporánea", La Ilustración Artística, de Barcelona, 11 de agosto. 
Pardo Bazán, Emilia (1903): San Francisco de Asís (siglo XIII); Obras Completas, tomos XXVII-XXVIII, Madrid, ed. da autora.

Pardo Bazán, Emilia (1912): "La vida contemporánea", La Ilustración Artística, 30 de setembro.

Pardo Bazán, Emilia (1999): "Apuntes autobiográficos", en Obras Completas, II, ed. D. Villanueva e José Manuel González Herrán, Madrid, Fundación J. A. de Castro.

Pardo Bazán, Emilia (1999): Los Pazos de Ulloa, en Obras Completas, vol. II, ed. D. Villanueva e J. M. González Herrán, Madrid: Fundación J. A. de Castro.

Pardo Bazán, Emilia (2002): Belcebú, en Obras Completas, vol. VI, ed. D. Villanueva e J. M. González Herrán, Madrid: Fundación J. A. de Castro.

Pardo Bazán, Emilia (2004): "El baile del Querubín", en Obras Completas, vol. VIII, ed. D. Villanueva e J. M. González Herrán, Madrid: Fundación J. A. de Castro.

Pardo Bazán, Emilia (2005): "La santa de Karnar", en Obras Completas, vol. IX, ed. D. Villanueva e J. M. González Herrán, Madrid: Fundación J. A. de Castro.

Pardo Bazán, Emilia (2005): "La Soledad", en Obras Completas, vol. X, ed. D. Villanueva e J. M. González Herrán, Madrid: Fundación J. A. de Castro.

Pardo Bazán, Emilia (2005): "La cana", en Obras Completas, vol. X, ed. D. Villanueva e J. M. González Herrán, Madrid: Fundación J. A. de Castro.

Pardo Bazán, Emilia (2011), "Cenizas", en Obras Completas, vol. XI, Cuentos dispersos I, ed. J. M. González Herrán, Madrid: Fundación J. A. de Castro.

Pardo Bazán, Emilia (2011), "La danza del peregrino", en Obras Completas, vol. XII, Cuentos dispersos II, ed. J. M. González Herrán, Madrid: Fundación J. A. de Castro.

Patiño Eirín, Cristina (2001): "Acerca del franciscanismo de Pardo Bazán", en A. Abuín González, J. Casas Rigall y J. M. González Herrán (eds.): Homenaje a Benito Varela Jácome, Santiago de Compostela: Universidade, pp. 455-471.

Rodríguez Mourelo, José (1880): "El diamante artificial", Revista de Galicia, no 9, 10 de mayo de 1880, pp. 78-79.

Rodríguez Carracido, José (1917): “La doctrina de la evolución en la Universidad de Santiago. Un recuerdo de mi vida estudiantil", en Estudios histórico-críticos de la ciencia española, Madrid, Impr. Alrededor del Mundo; [ed. facísmil, Barcelona, Alta Fulla, 1988].

Simón Palmer, M. Carmen (1998): "Trece días en la vida de Emilia Pardo Bazán. Manuscrito inédito", en Estudios de Literatura española de los siglos XIX y XX. Homenaje a Juan María Díez Taboada, Madrid: C.S.I.C., pp. 399-404.

Varela, José Luis (2001): E. Pardo Bazán: Epistolario a Giner de los Ríos, Madrid: Artegraf. 
Varela Jácome, Benito (1973): Estructuras novelísticas de Emilia Pardo Bazán, Santiago de Compostela: C.S.I.C. 